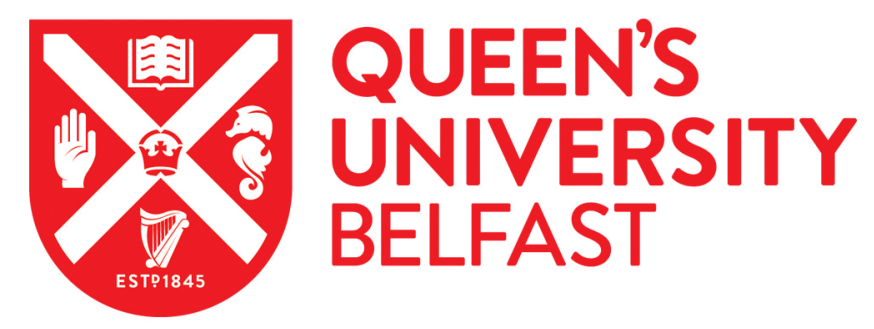

\title{
Effects of temperature and strain rate on the tensile behaviors of SIMP steel in static lead bismuth eutectic
}

Liu, J., Yan, W., Sha, W., Wang, W., Shan, Y., \& Yang, K. (2016). Effects of temperature and strain rate on the tensile behaviors of SIMP steel in static lead bismuth eutectic. Journal of Nuclear Materials, 473, 189-196. https://doi.org/10.1016/j.jnucmat.2016.02.032

Published in:

Journal of Nuclear Materials

Document Version:

Peer reviewed version

Queen's University Belfast - Research Portal:

Link to publication record in Queen's University Belfast Research Portal

Publisher rights

(c) 2016 Elsevier B.V. This manuscript version is made available under the CC-BY-NC-ND 4.0 licensehttp://creativecommons.org/licenses/by$\mathrm{nc}-\mathrm{nd} / 4.0 /$,which permits distribution and reproduction for non-commercial purposes, provided the author and source are cited.

\section{General rights}

Copyright for the publications made accessible via the Queen's University Belfast Research Portal is retained by the author(s) and / or other copyright owners and it is a condition of accessing these publications that users recognise and abide by the legal requirements associated with these rights.

Take down policy

The Research Portal is Queen's institutional repository that provides access to Queen's research output. Every effort has been made to ensure that content in the Research Portal does not infringe any person's rights, or applicable UK laws. If you discover content in the Research Portal that you believe breaches copyright or violates any law, please contact openaccess@qub.ac.uk. 
First author: Jian Liu

Email addresses: jliu12b@imr.ac.cn

Corresponding author: Ke Yang

Email addresses: kyang@imr.ac.cn

Corresponding author address: Institute of Metal Research, Chinese Academy of Sciences, 72 Wenhua Road,

Shenyang, China 110016 Tel.:+86 $2423971628 \quad$ Fax: +86 2423971628

\title{
Effects of temperature and strain rate on the tensile behaviors of SIMP steel in static lead bismuth eutectic
}

\author{
Jian Liü, ${ }^{\mathrm{a}, \mathrm{b}}$, Wei Yan ${ }^{\mathrm{a}}$, Wei Sha ${ }^{\mathrm{c}}$, Wei Wang ${ }^{\mathrm{a}}$, Yiyin Shan ${ }^{\mathrm{a}}$, Ke Yang ${ }^{\mathrm{a},{ }^{*}}$ \\ ${ }^{\text {a }}$ Institute of Metal Research, Chinese Academy of Sciences, Shenyang 110016, China \\ ${ }^{\mathrm{b}}$ University of Chinese Academy of Sciences, Beijing 100049, China \\ ${ }^{\mathrm{c}}$ School of Planning, Architecture and Civil Engineering, Queen's University Belfast, Belfast BT9 \\ $5 \mathrm{AG}, \mathrm{UK}$ \\ ${ }^{*}$ Corresponding author. Tel.: +86 24 23971628; fax: +86 2423971628 \\ E-mail address: kyang@imr.ac.cn (Ke Yang)
}

\begin{abstract}
In order to assess the susceptibility of candidate structural materials to liquid metal embrittlement, this work investigated the tensile behaviors of ferritic-martensitic steel in static lead bismuth eutectic (LBE). The tensile tests were carried out in static lead bismuth eutectic under different temperatures and strain rates. Pronounced liquid metal embrittlement phenomenon is observed between $200{ }^{\circ} \mathrm{C}$ and $450{ }^{\circ} \mathrm{C}$. Total elongation is reduced greatly due to the liquid metal embrittlement in LBE environment. The range of ductility trough is larger under slow strain rate tensile (SSRT) test.
\end{abstract}

Keywords: electron microscopy; light microscopy; LBE; steel; oxidation

\section{Introduction}

The concept of Accelerator Driven Sub-critical (ADS) system [1-3] was proposed in 1990s to transmute the nuclear waste. The strategic objective of ADS is to transmute (burn up) long-lived minor actinide in order to reduce the amount and the radiotoxicity of high radio-toxicity level nuclear waste, and to close the fuel cycle including minor actinides [3]. In ADS, the neutrons are 
produced to transmute the long-lived elements into short-lived elements $[4,5]$. Over the sodium alloy used in sodium cooled fast reactor, the lead and lead alloy, especially the lead-bismuth eutectic (LBE), are considered as the primary candidate for coolant and/or spallation target of ADS.

Many candidate structural materials suffer from serious corrosion from LBE at elevated temperatures. However, low melting point $\left(126^{\circ} \mathrm{C}\right)$ of LBE enables ADS to operate in the lower temperature range than pure lead. These lower operating temperatures, in the range of $250-550{ }^{\circ} \mathrm{C}$, may be low enough to reduce the corrosion susceptibility making it possible to use commercially available high strength, creep resistant steels [6]. In addition, the currently envisaged approach to mitigating liquid metal corrosion relies on combining lower operating temperatures with a precise control of the concentration of dissolved oxygen in the heavy liquid metal, as it has been shown that the formation of oxides scales on the steel surface minimizes the undesirable steel dissolution [7].

Apart from the corrosion issues, the challenge of liquid metal embrittlement (LME) is mostly in fulfilling preconditions. The phenomenon of LME is the drastic reduction in strength and ductility of original ductile solid metal in contact with special low melting point liquid metal directly [8-11].

9\% Cr ferritic-martensitic steels, which are considered as the structural materials for ADS, are prone to the LME effects. The mechanical properties of steels deteriorate when stressed in liquid metal environment [12-14]. Literature [10,15] shows that the total elongation, strength, fracture energy, creep-rupture, ductility, fatigue life of structural materials are deteriorated by LBE. The elongation at room temperature after pre-exposure to LBE also degrades [16]. Some premature failure of structure material will occur without necking [17]. So, it is necessary to avoid the possible LME phenomenon for the long-term safe operation of ADS.

LME phenomenon is pronounced especially in the range of $300-550{ }^{\circ} \mathrm{C}$ according to literature [6], coinciding with the operation temperature range of experimental ADS system. The susceptibility of structural materials to LME is unacceptable for ADS long-term safe operation criterion. So, it is important to investigate the LME phenomenon in order to ensure the compatibility of structural materials with LBE.

By now, a large number of investigations on LME have been carried out. Although much experimental data is available, the mechanism of LBE embrittlement effects on martensitic steel is not yet clear [18]. The reason is that the embrittlement phenomenon is complicated. The LME phenomenon depends on many parameters [6, 19], including temperature, composition, 
microstructure, strain rate, hardness, stress concentration and surface state. Nicaise et al. [20] considered LME as the decrease of surface energy by wetting. Others attributed it to the dynamic strain aging (DSA) or liquid metal environment assisted crack (EAC) nucleation and branching [8, 21], stress assisting liquid metal to dissolve and transport solid metal atoms, complex oxidation reaction, etc. $[8-11,13,22]$.

The aim of this experiment is to assess the susceptibility of SIMP steel to LME in a range of simulated operating conditions. The tensile behaviors of SIMP steel in static LBE are investigated at different temperatures. The total elongation as a function of temperature was measured to find the ductility trough. The LME likely occurs under slow strain rate tensile (SSRT) conditions [18, 19, 23, 24]. Long et al. [25] reported that the T91 steel tempered at low temperature demonstrated more pronounced susceptibility at SSRT. So, the tensile tests were performed under different strain rates to investigate the possible LME phenomenon.

Previous studies $[5,19]$ show that ferritic-martensitic steels are more prone to LME than austenitic steel $316 \mathrm{~L}$. The elongation degrades greatly when tensile tests were carried out at the temperature interval of $300-550{ }^{\circ} \mathrm{C}$, i.e., the ductility trough $[6,19,24]$. The candidate ADS structural materials, such as T91, will serve in irradiation environment and be subject to irradiative damages, such as swelling, creep, hardening and embrittlement. Previous tests [23, 26] show that after irradiation or tempering at low temperatures, the steels with higher hardness are more susceptibility to LME.

A previous study used T91 tempered at low temperatures and mentioned the difficulties in handling radioactive materials and the lack of irradiated specimens [25]. Literature [20, 25, 27] shows that $\mathrm{T} 91$ is sensitive to LME phenomenon after tempering at $500{ }^{\circ} \mathrm{C}$ in LBE and lead. In this experiment, SIMP steel was tempered at $500{ }^{\circ} \mathrm{C}$ to obtain high hardness. It is possible for SIMP steel to be more prone to LME phenomenon than T91 because of the higher carbon and other alloying element contents.

\section{Experimental procedure}

\subsection{Materials and specimens}

The steel employed in this research is the newly developed SIMP steel. The chemical composition of the experimental steel is shown in Table 1. The SIMP steel was normalized at 1050 ${ }^{\circ} \mathrm{C}$ for $30 \mathrm{~min}$, and then tempered at $500{ }^{\circ} \mathrm{C}$ for $90 \mathrm{~min}$. 
Table 1 Chemical composition of the experimental SIMP steel (wt\%)

\begin{tabular}{cccccccc}
\hline $\mathrm{C}$ & $\mathrm{Cr}$ & $\mathrm{W}$ & $\mathrm{Mn}$ & $\mathrm{Si}$ & $\mathrm{V}$ & $\mathrm{Nb}$ & $\mathrm{Ta}$ \\
\hline 0.2 & 10.7 & 1.2 & 0.5 & 1.4 & 0.2 & 0.01 & 0.1 \\
\hline
\end{tabular}

The original microstructure of SIMP steel is the tempered martensite. The average size of primary austenite grains is approximately $20 \mu \mathrm{m}$. The lath microstructure of the SIMP steel is shown in Fig.1. Ref. [28] gives a detailed analysis of carbide precipitation in this type of steels.

The cylindrical tensile specimens with gauge length of $25 \mathrm{~mm}$ and diameter of $4 \mathrm{~mm}$ were machined. The dimension of the tensile specimens is shown in Fig.2. The native oxide film on the gauge of the tensile specimens was removed by grinding using abrasive paper of 2000 \# prior to tensile tests. The purpose of removing the oxide film is to improve the contact between the steel surface and LBE.

The liquid lead-bismuth alloy employed for the tests is at the eutectic composition, $55.5 \mathrm{wt} \%$ $\mathrm{Bi}$ and $44.5 \mathrm{wt} \% \mathrm{~Pb}$. The liquid lead-bismuth eutectic (LBE) was greatly purified. The trace content of impurities are listed below: $\mathrm{Mg}, \mathrm{Al}, \mathrm{Cr}, \mathrm{Ni}, \mathrm{Cu}, \mathrm{Zn}, \mathrm{As}, \mathrm{Sb}, \mathrm{Cd}$ each $<1 \mathrm{ppm}, \mathrm{Sn}<3 \mathrm{ppm}, \mathrm{Fe}$, $\mathrm{Ag}$ each $<5 \mathrm{ppm}, \mathrm{Si}<10 \mathrm{ppm}$. Nitrogen and carbon are not detected in LBE.

The LBE employed was machined into cylindrical ingots by electrical discharge machining (EDM) to fit into the tank before experiments. The cylindrical LBE ingots were ground by sand paper to remove oxide film, cleaned in ethanol in an ultrasonic machine, and then dried in air and sealed to avoid oxidization. No special wetting solutions were used to improve the contact between LBE and the surface.

\subsection{Testing device and procedure}

The tensile tests were performed at two different cross head displacement rate of $1.5 \mathrm{~mm} / \mathrm{min}$ and $0.15 \mathrm{~mm} / \mathrm{min}$, corresponding to initial strain rates of $1.25 \times 10^{-3} \mathrm{~s}^{-1}$ and $1.25 \times 10^{-4} \mathrm{~s}^{-1}$, respectively. The tensile specimens were separated into two groups. Group-I was tested at the cross head displacement rate of $1.5 \mathrm{~mm} / \mathrm{min}$. The SSRT tests of Group-II were carried out at the displacement rate of $0.15 \mathrm{~mm} / \mathrm{min}$. The tensile tests to assess the possible LME phenomenon were performed between $200{ }^{\circ} \mathrm{C}$ and $500{ }^{\circ} \mathrm{C}$. It is difficult to obtain the temperature below $200{ }^{\circ} \mathrm{C}$ accurately due to the limit of the temperature controlling system, so no tensile test was performed below $200{ }^{\circ} \mathrm{C}$.

The tensile tests were performed in a MTS mechanical testing machine with $50 \mathrm{kN}$ load 
capacity. A special device for tensile testing in LBE was designed and made, which is composed of three components: a down cross head, a long upper cross head and a pipe. The down cross head is welded to the pipe for LBE storage. The pipe is long enough to contain adequate amount of LBE and the gauge length of the tensile specimens was immersed in LBE during testing. A sketch of the tensile set-up for the LME test is shown in Fig.3. Similar test set-ups had been used to assess the LME of T91 in LBE and lead [20, 29].

The atmosphere in experimental set-up was controlled through Ar gas purging. The oxygen concentration in LBE varies at different temperatures. According to literature, the oxygen concentration in LBE is lower than $1 \mathrm{ppm}$ at $250{ }^{\circ} \mathrm{C}$ [18].

After rupture, the residual LBE adhered to the fracture surfaces was removed in the following way. After extracting from the melt, the broken tensile specimens were cleaned in the liquid mixture of acetic acid $\left(\mathrm{CH}_{3} \mathrm{COOH}\right)$, hydrogen peroxide $\left(\mathrm{H}_{2} \mathrm{O}_{2}\right)$ and ethanol $\left(\mathrm{C}_{2} \mathrm{H}_{5} \mathrm{OH}\right)$ at a ratio of 1:1:1. This solution removed solid LBE without affecting the fracture morphology. After the residual LBE on the surfaces was removed, the fracture surface of the samples was analyzed by using scanning electron microscopy (SEM).

The influence of liquid LBE on the tensile properties of SIMP steel is determined by comparing the tensile test results in LBE and Ar gas environments.

\section{Results}

\subsection{Tensile tests}

\subsubsection{Tensile curves}

In LBE, the tensile specimens ruptured in a brittle mode. A photograph of one tensile specimen is shown in Fig.4. The total elongation and area reduction are significantly reduced. No obvious necking is observed.

To examine the embrittlement effects of the liquid LBE at different temperatures, the tensile curves of SIMP in both Ar and LBE environments are shown together for the purpose of comparison. Tensile curves of SIMP at the same temperature are shown in Fig. 5 to reveal the LME phenomenon.

The tensile curves reveal that the embrittlement phenomenon occurs at $250{ }^{\circ} \mathrm{C}$ and disappears at $450{ }^{\circ} \mathrm{C}$. When tested in the interval of $250-400{ }^{\circ} \mathrm{C}$, it can be found that the premature fracture occurs during tensile testing, for some specimens even before necking starts. The tensile curves obtained at $500{ }^{\circ} \mathrm{C}$ in $\mathrm{Ar}$ and LBE environments match well. 


\subsubsection{Total elongation}

The temperature interval where the elongation decreases is defined as "ductility trough". Detailed total elongation data is given in Fig.6. The diagram shows significant reduction in total elongation in LBE environment. The total elongation obtained in LBE recovers at $450{ }^{\circ} \mathrm{C}$.

When tested at $500{ }^{\circ} \mathrm{C}$, the total elongation in LBE is $18 \%$, the same as that in Ar environment.

\subsubsection{Fracture analysis}

The SEM observation was performed on all the broken specimens to identify the fracture mode. The micrographs on specimens ruptured in both Ar and LBE at selected temperatures are shown in Fig.7. The changes of tensile behaviors correlate with the fracture feature.

All of the specimens tested in Ar environment show ductile fracture and dimples. The size of dimples on the fracture surface increases with increasing test temperature. The samples show more necking prior to fracture. Cup and cone shape characteristic of ductile failure can be found when ruptured in Ar gas environment.

The samples tested in liquid LBE present generally brittle fracture, as seen in the right column of Fig.7 for specimens tested in LBE. The embrittlement phenomenon is drastic and the samples broke after small plastic deformation. The fracture surfaces of the specimens tested in LBE have clear river patterns. However, other samples out of ductility trough have dimples and indicate fully ductile fracture feature.

The locations of crack initiation are found at the margin of fracture surfaces, not the center. The cracks propagated along grain boundaries and the tensile specimens broke in brittle manner. Ye et al. consider that LBE promotes the formation of radial cracks and of brittle fracture in many localized zones [30].

Sometimes, it is difficult to find whether LME occurs or not just by comparing tensile curves obtained in LBE and Ar. The brittle fracture observation shows more clearly LME. In the overview of fracture surface at $200{ }^{\circ} \mathrm{C}$ obtained in LBE, one can see that the specimen ruptures in ductile mode and shows obvious necking. The fracture surface contains dimples. However, it is interesting to find a small area showing brittle rupture feature at the peripheral of fracture surface. River pattern characteristics are observed in this area. The presence of mixed brittle-ductile fracture indicates that the onset of the ductility trough is $200{ }^{\circ} \mathrm{C}$ in tensile test. 


\subsubsection{Tensile curves}

Some previous investigations on the T91 susceptibility to LME were performed under SSRT according to literature $[18,19,23,24]$. They reveal that T91 is more sensitive to LME in SSRT. The present SSRT results of SIMP agree with the previous T91 tests.

Despite a small deviation due to experimental scatter, most specimens in LBE ruptured prior to those in Ar gas environment. When tensile tests were carried out at the strain rate of $1.25 \times 10^{-3} \mathrm{~s}^{-}$

${ }^{1}$, the LME phenomenon occurs in the interval of $250-400{ }^{\circ} \mathrm{C}$. However, when the tensile tests were performed under the strain rate of $1.25 \times 10^{-4} \mathrm{~s}^{-1}$, the LME phenomenon appears between 200-450 ${ }^{\circ} \mathrm{C}$. The slow strain rate tensile tests enlarge the ductility trough. The ductility recovers at $500{ }^{\circ} \mathrm{C}$ in both tensile tests in spite of the different strain rates. Selected curves of SSRT are shown in Fig.8.

\subsubsection{Total elongation}

Fig.9 summarizes the temperature dependency of total elongation tested in both $\mathrm{Ar}$ and LBE environments. One can see that the ductility obtained in LBE is reduced greatly between 200 and $450{ }^{\circ} \mathrm{C}$ compared to that in Ar gas environment. The total elongation in LBE recovers and returns to the same level as that in Ar environment at $500{ }^{\circ} \mathrm{C}$. The SSRT tests in LBE were not performed below $200{ }^{\circ} \mathrm{C}$, so the real onset of the ductility trough is in fact not known.

\subsubsection{Fracture analysis}

To examine the influence of the strain rate, selected Group-II fracture surfaces are shown in Fig.10. The SEM examination indicates that the fracture modes of specimens tested in Ar at all temperatures are ductile, as shown with the three example tests in the left column of Fig.10. The fracture surfaces of the specimens tested in LBE illustrate the embrittlement effect, showing brittle fracture surface. Flat and perpendicular fracture dominates the fracture surface.

Detailed SEM examination of the fracture surface reveals that the SIMP steel tested in gas environment (see left column in Fig.7 and Fig.10) has dimples and shows the cup and cone shape characteristic of ductile failure. Obvious necking can be observed.

The gauge diameter of the SIMP tensile specimens in LBE is $4 \mathrm{~mm}$. The diameter of the ruptured specimens can be seen in the macro views of SEM fractural analysis. In most cases, the diameter is nearly the same as original specimens, as depicted in Fig.4, Fig.7 and Fig.10. It indicates that the area reduction rates are decreased. There is little necking of the specimen prior to fracture. In comparison, the fracture surfaces obtained in $\mathrm{Ar}$ at the temperature range of $200-450{ }^{\circ} \mathrm{C}$ show 
obvious necking.

In both Group-I and II, the observation of fracture tested in liquid metal environment shows no penetration of LBE. There is no great difference on fracture surface between tensile and SSRT tests in the same environment.

\section{Discussion}

The effects of liquid metal embrittlement on ductile metals have been investigated for many years. It is defined as elongation reduction of the ductile metals when in contact with special liquid metals. However, the mechanism of embrittlement by lead and LBE is still unclear.

The LME phenomenon is more evident when the specimens are loaded in the center of ductility trough and slow strain rate tests where several lateral cracks are visible on the fracture surface. The secondary cracks are observed on the fracture surface. The nucleation of river pattern cracks is found to locate on the periphery of fracture surface. The initiation of cracks at the margin of fracture surface is observed. The cracks propogated and branched during tensile testing, which indicates that the interactions between liquid metal and solid metal resulted in LME.

The river pattern fracture on the surface of the tensile specimens indicates clearly LBE embrittlement effects at temperature over $250^{\circ} \mathrm{C}$ [18]. Only at a given temperature interval does the LME phenomenon appear. The presence of ductility trough might be due to the synergetic effects of liquid metal atoms and temperature. It is known that wetting is a prerequisite for LME to occur. In this experiment, all the specimens tested in Ar gas environment rupture in a ductile mode. The LME will not appear if the temperature is too low for wetting to occur. With temperature increase, good wetting on solid-liquid interface is obtained and the LME occurs. At this temperature range, the ductility is not high enough and brittle fracture dominates. When the temperature is further increased to higher levels, the ductility of materials increases and exceeds brittle fracture effects. Ductile fracture dominates the fracture pattern, the ductility recovers and LME disappears.

The extent of the brittle fracture decreases with the increase of the cross-head displacement rate [18]. A low strain rate encourages wetting of fresh metal surface that appears by breaking the oxide layer on the samples and allowing the penetration of LBE [24]. The LME effect is more pronounced for the lower rate due to the longer contact time. However, the cracks are observed on fracture surfaces, as shown in Fig.7 and Fig.10. It is possible for liquid metal atoms to penetrate into the cracks after rupture and before extracting the broken specimens from melt. Some advanced 
analysis techniques such as FIB and TEM are used to find the penetration of LBE into martensitic laths [31].

Literature shows that T91 is prone to $\mathrm{LME}$ after being tempered at $760{ }^{\circ} \mathrm{C}, 600{ }^{\circ} \mathrm{C}$ and $500{ }^{\circ} \mathrm{C}$ [25]. Tests of LME of SIMP steel are new. Further investigations are ongoing.

\section{Conclusions}

The tensile behaviors of SIMP steel in static LBE are investigated for the first time. Some conclusions can be reached based on the results of the experiments. It is revealed that the SIMP is susceptible to LME at different strain rates and temperatures. When tensile tested in LBE, the LME phenomenon is pronounced at the temperature interval of $250-400{ }^{\circ} \mathrm{C}$. The total elongation is reduced greatly. The ductility trough is wider under SSRT. The tensile specimens rupture in brittle manner without obvious necking. In comparison, all of the specimens testing in Ar gas environment broke in a ductile manner. When tested at $500{ }^{\circ} \mathrm{C}$, the ductility recovers, the fracture turns into ductile and dimples are present in both liquid metal and Ar gas environment.

\section{Acknowledgments}

This work was financially supported by a subtopic (XDA03010301, XDA03010302) of Advanced Fission Energy Program-ADS Transmutation System, Chinese Academy of Sciences Strategic Priority Research Program (XDA03010000).

\section{References}

[1] A.P.A. Mustari, M. Takahashi, Prog. Nucl. Energ., 53 (2011) 1073-1077.

[2] M. Takahashi, R. Sa, A. Pramutadi, E. Yamaki-Irisawa, in: Z. Suud, A. Waris (eds.), 3rd International Conference on Advances in Nuclear Science and Engineering, 2012, pp. 39-49.

[3] J.U. Knebel, X. Cheng, C.H. Lefhalm, G. Muller, G. Schumacher, J. Konys, H. Glasbrenner, Nucl. Eng. Des., 202 (2000) 279-296.

[4] A. Ahmad, S.J. Steer, G.T. Parks, Energ. Convers. Manage., 69 (2013) 181-190.

[5] C. Fazio, I. Ricapito, G. Scaddozzo, G. Benamati, J. Nucl. Mater., 318 (2003) 325-332.

[6] J. Van den Bosch, G. Coen, P. Hosemann, S. Maloy, J. Nucl. Mater., 429 (2012) 105-112.

[7] K. Lambrinou, V. Koch, G. Coen, J. Van den Bosch, C. Schroer, J. Nucl. Mater., 450 (2014) 244-255.

[8] T. Auger, G. Lorang, S. Guérin, J.-L. Pastol, D. Gorse, J. Nucl. Mater., 335 (2004) 227-231.

[9] A. Hojna, F. Di Gabriele, J. Nucl. Mater., 413 (2011) 21-29.

[10] D. Gorse, T. Auger, J.-B. Vogt, I. Serre, A. Weisenburger, A. Gessi, P. Agostini, C. Fazio, A. Hojna, 
F. Di Gabriele, J. Nucl. Mater., 415 (2011) 284-292.

[11] J. Van den Bosch, P. Hosemann, A. Almazouzi, S.A. Maloy, J. Nucl. Mater., 398 (2010) 116-121.

[12] J. Van den Bosch, R.-W. Bosch, D. Sapundjiev, A. Almazouzi, J. Nucl. Mater., 376 (2008) 322-329.

[13] A. Legris, G. Nicaise, J.-B. Vogt, J. Foct, J. Nucl. Mater., 301 (2002) 70-76.

[14] M.L. Martin, T. Auger, D.D. Johnson, I.M. Robertson, J. Nucl. Mater., 426 (2012) 71-77.

[15] T. Auger, Z. Hamouche, L. Medina-Almazan, D. Gorse, J. Nucl. Mater., 377 (2008) 253-260.

[16] C. Fazio, OECD/NEA (Organisation for Economic Cooperation and Development/Nuclear Energy Association), 2007.

[17] J. Van den Bosch, G. Coen, W. Van Renterghem, A. Almazouzi, J. Nucl. Mater., 396 (2010) 57-64.

[18] Y. Dai, B. Long, F. Groeschel, J. Nucl. Mater., 356 (2006) 222-228.

[19] Z. Hamouche-Hadjem, T. Auger, I. Guillot, D. Gorse, J. Nucl. Mater., 376 (2008) 317-321.

[20] G. Nicaise, A. Legris, J.B. Vogt, J. Foct, J. Nucl. Mater., 296 (2001) 256-264.

[21] F. Di Gabriele, A. Doubková, A. Hojná, J. Nucl. Mater., 376 (2008) 307-311.

[22] T. Naoe, Y. Yamaguchi, M. Futakawa, J. Nucl. Mater., 431 (2012) 133-139.

[23] B. Long, Y. Dai, N. Baluc, J. Nucl. Mater., 431 (2012) 85-90.

[24] J. Van den Bosch, D. Sapundjiev, A. Almazouzi, J. Nucl. Mater., 356 (2006) 237-246.

[25] B. Long, Z. Tong, F. Groeschel, Y. Dai, J. Nucl. Mater., 377 (2008) 219-224.

[26] J. Van den Bosch, G. Coen, R.W. Bosch, A. Almazouzi, J. Nucl. Mater., 398 (2010) 68-72.

[27] A. Legris, G. Nicaise, J.B. Vogt, J. Foct, D. Gorse, D. Vancon, Scripta Mater., 43 (2000) 997-1001.

[28] Ouadie Hamdane, Ingrid Proriol Serre, Jean-Bernard Vogt, Nicolas Nuns, Mater. Chem. Phys., 145 (2014) 243-249.

[29] J.L. Pastol, P. Plaindoux, C. Leroux, S. Guerin, S.B. Goryachev, D. Gorse, F. Gamaoun, M. Dupeux, V. Ghetta, J. Phys. IV, 12 (2002) 203-216.

[30] Changqing Ye, Jean-Bernard Vogt, Ingrid Proriol Serre, Mater. Sci. Eng. A, 608 (2014) 242-248.

[31] S. Hemery, T. Auger, J.L. Courouau, F. Balbaud-Celerier, Corros. Sci., 76 (2013) 441-452. 

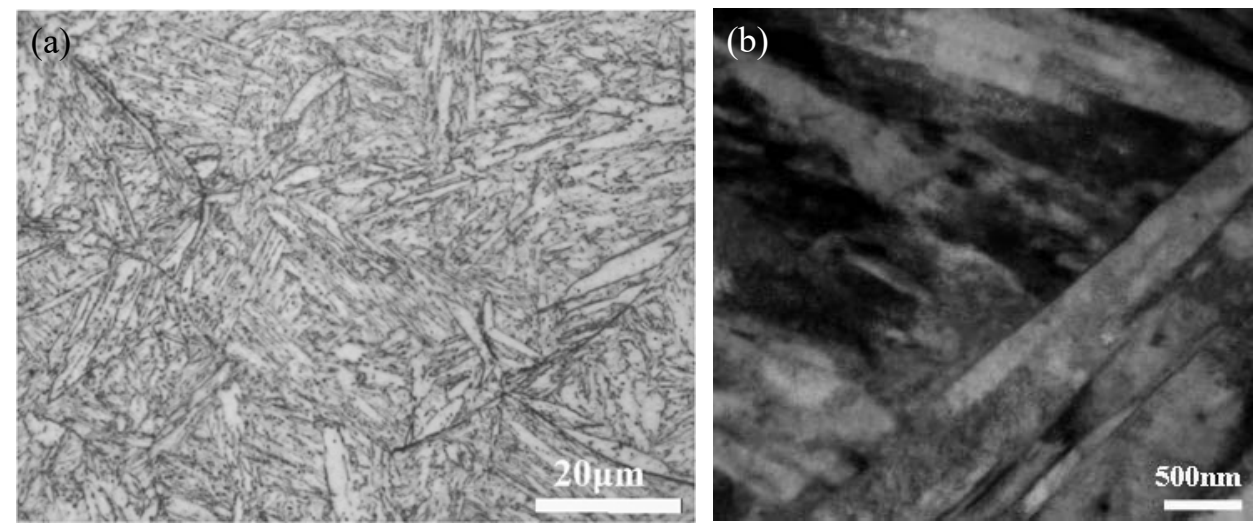

Fig. 1 Microstructure of SIMP. (a) Optical; (b) TEM. 


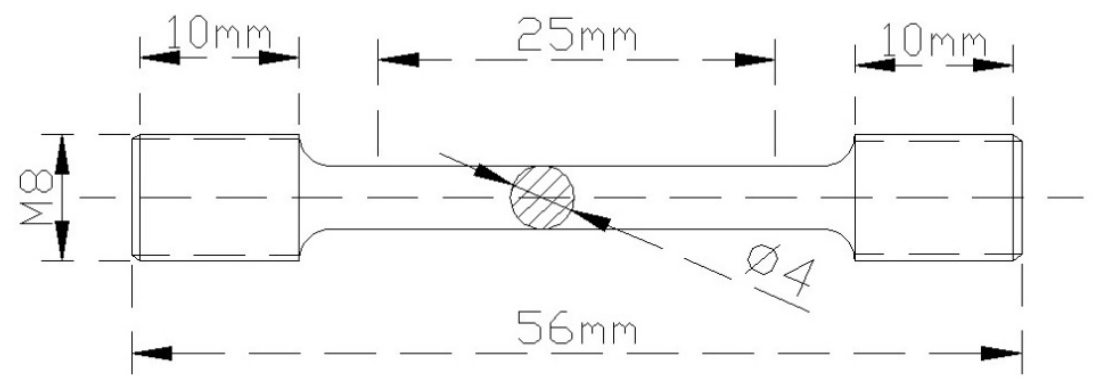

Fig. 2 Specimen for tensile tests. 

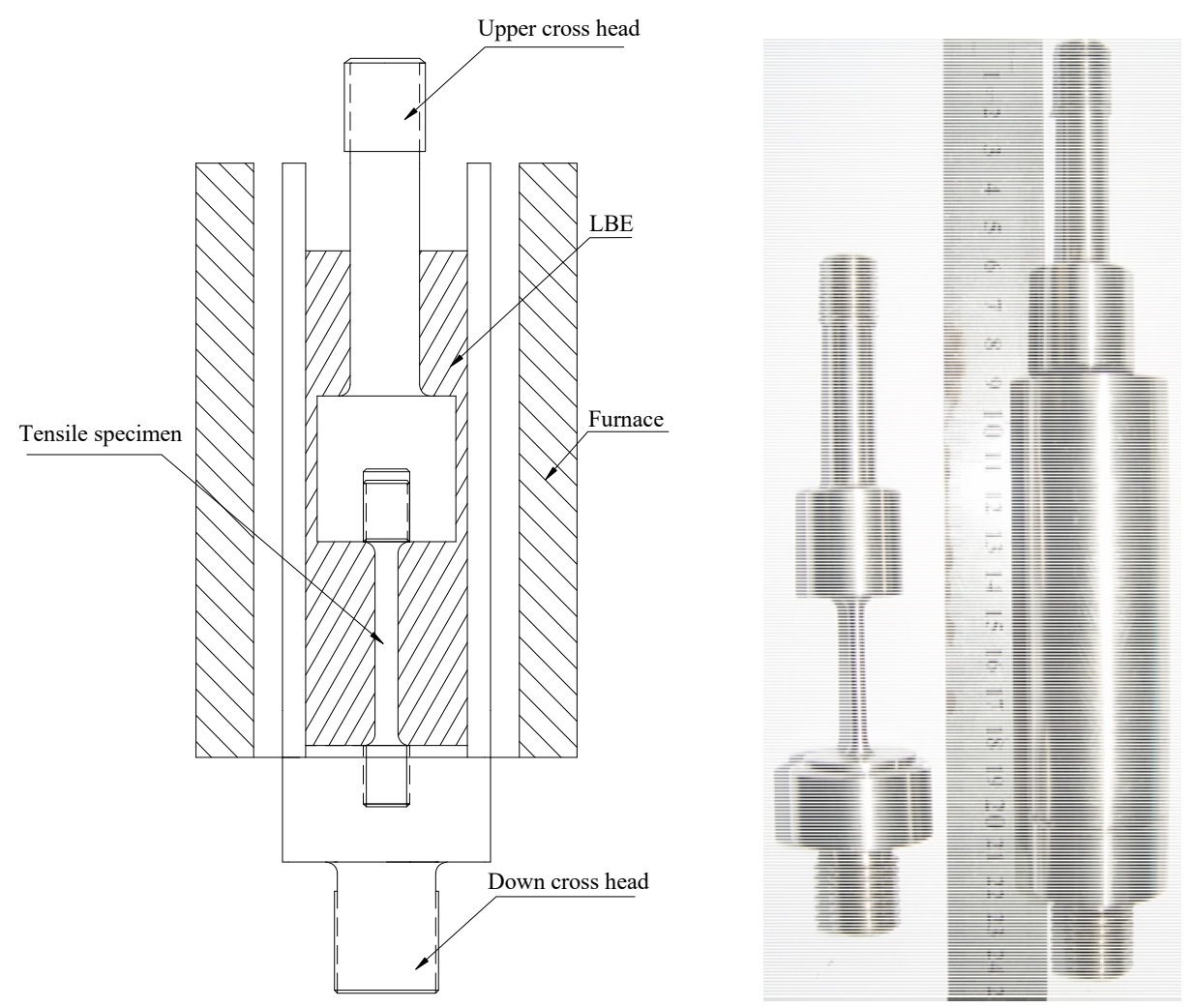

Fig. 3 Schematic diagram and a photograph of experimental set-up. 


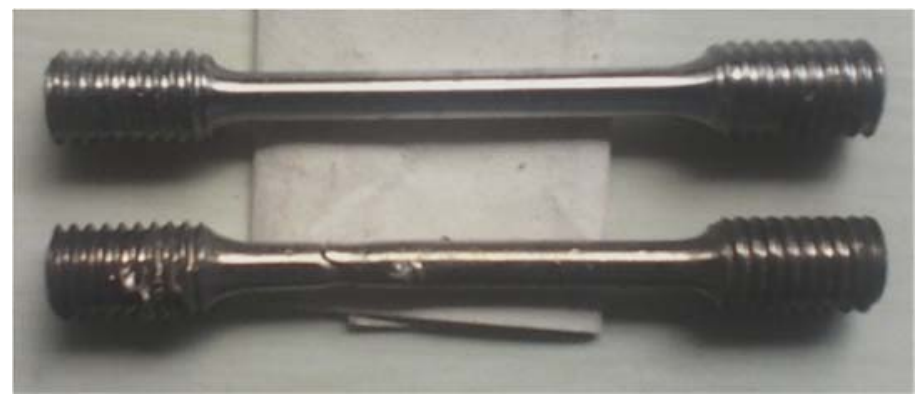

Fig. 4 Tensile specimens before and after fracture in LBE. 

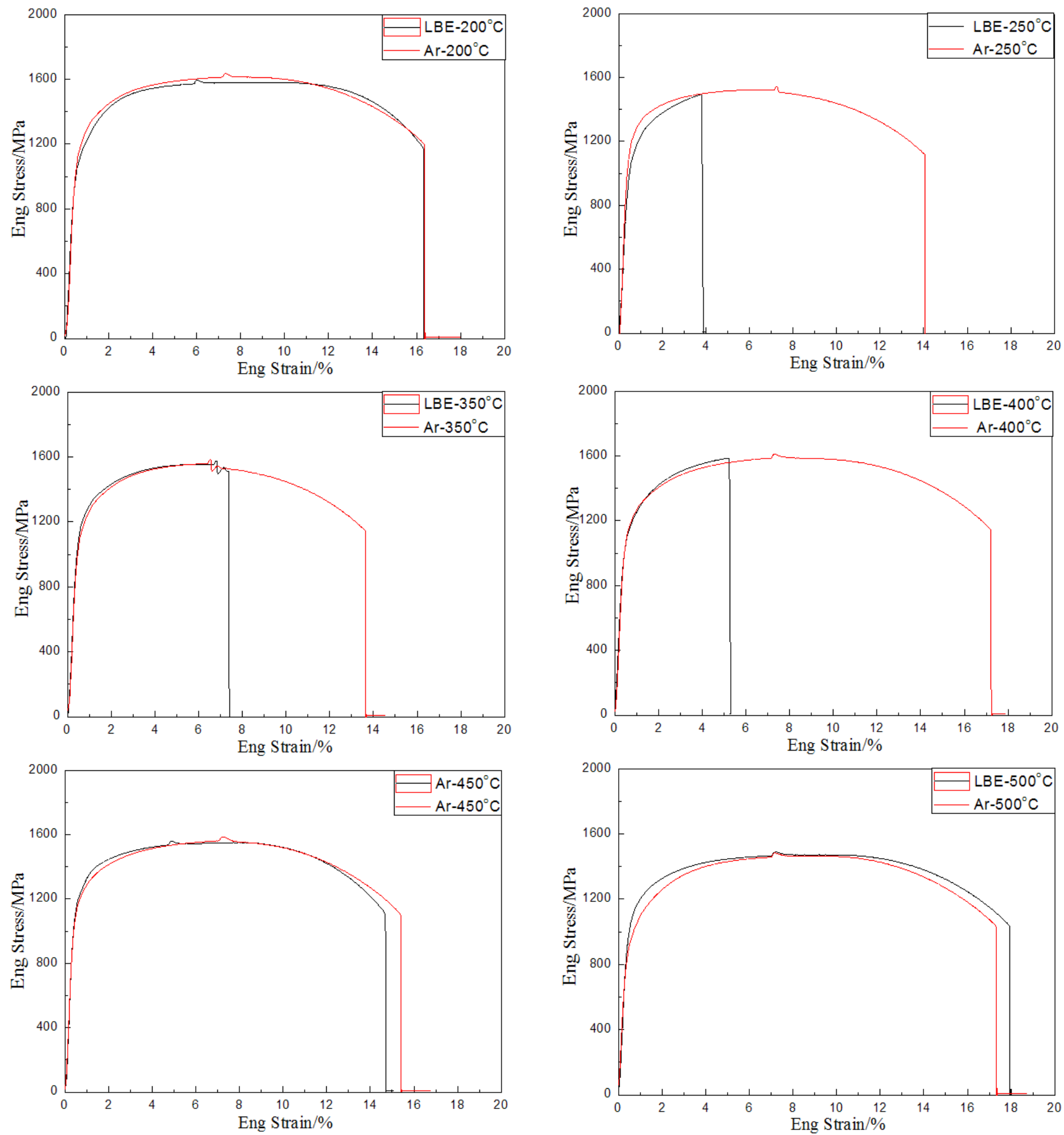

Fig. 5 Tensile curve of SIMP at different temperatures. 


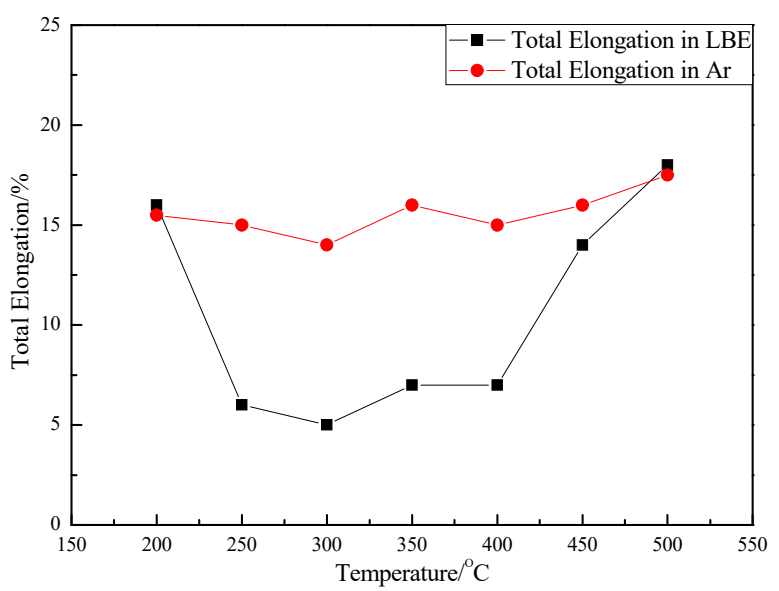

Fig. 6 Total elongation of SIMP at different temperatures. 

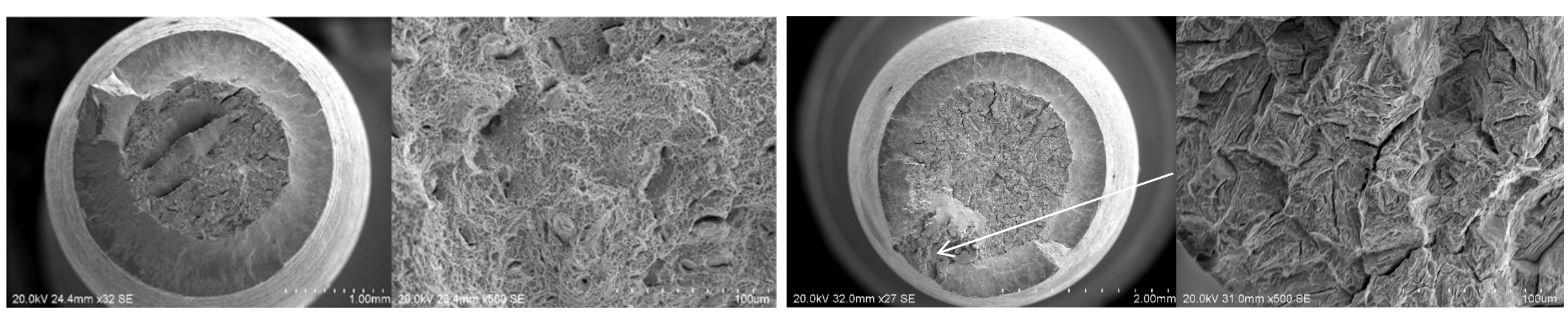

$200{ }^{\circ} \mathrm{C}$
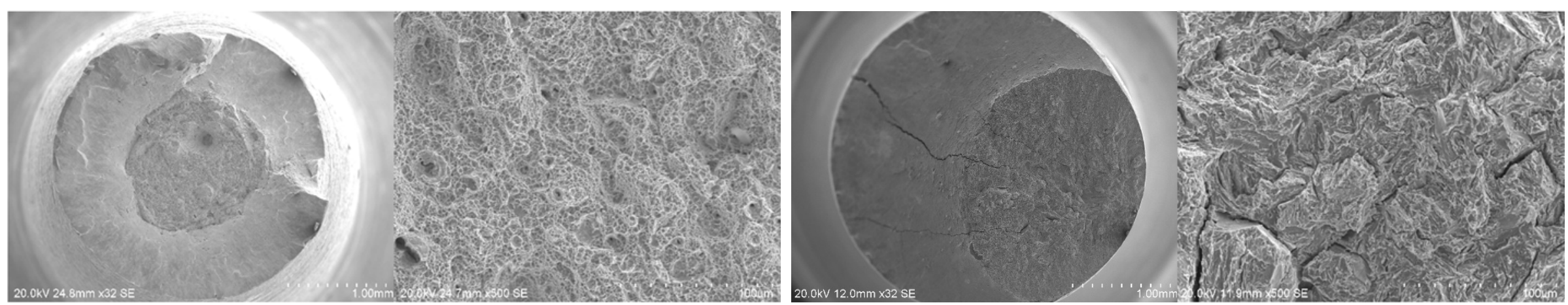

$350{ }^{\circ} \mathrm{C}$
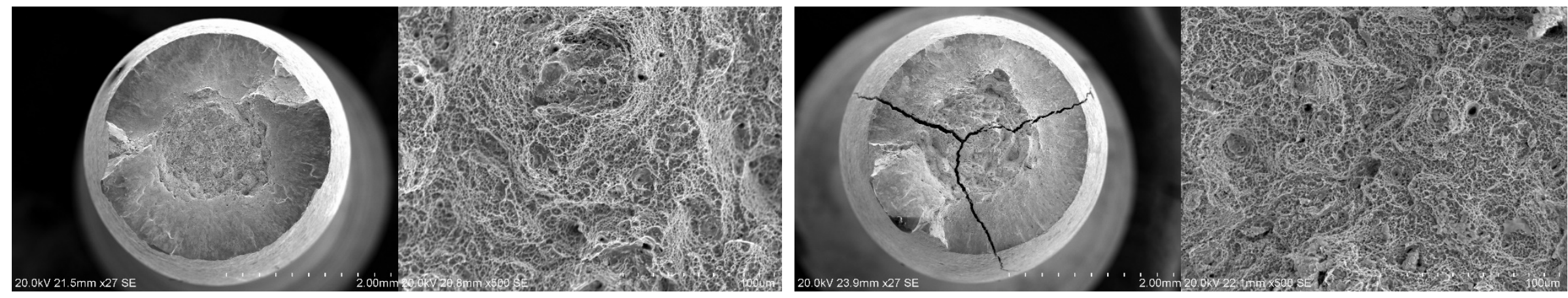

$500{ }^{\circ} \mathrm{C}$

Fig. 7 Fracture analysis of SIMP after tensile test at different temperatures. 

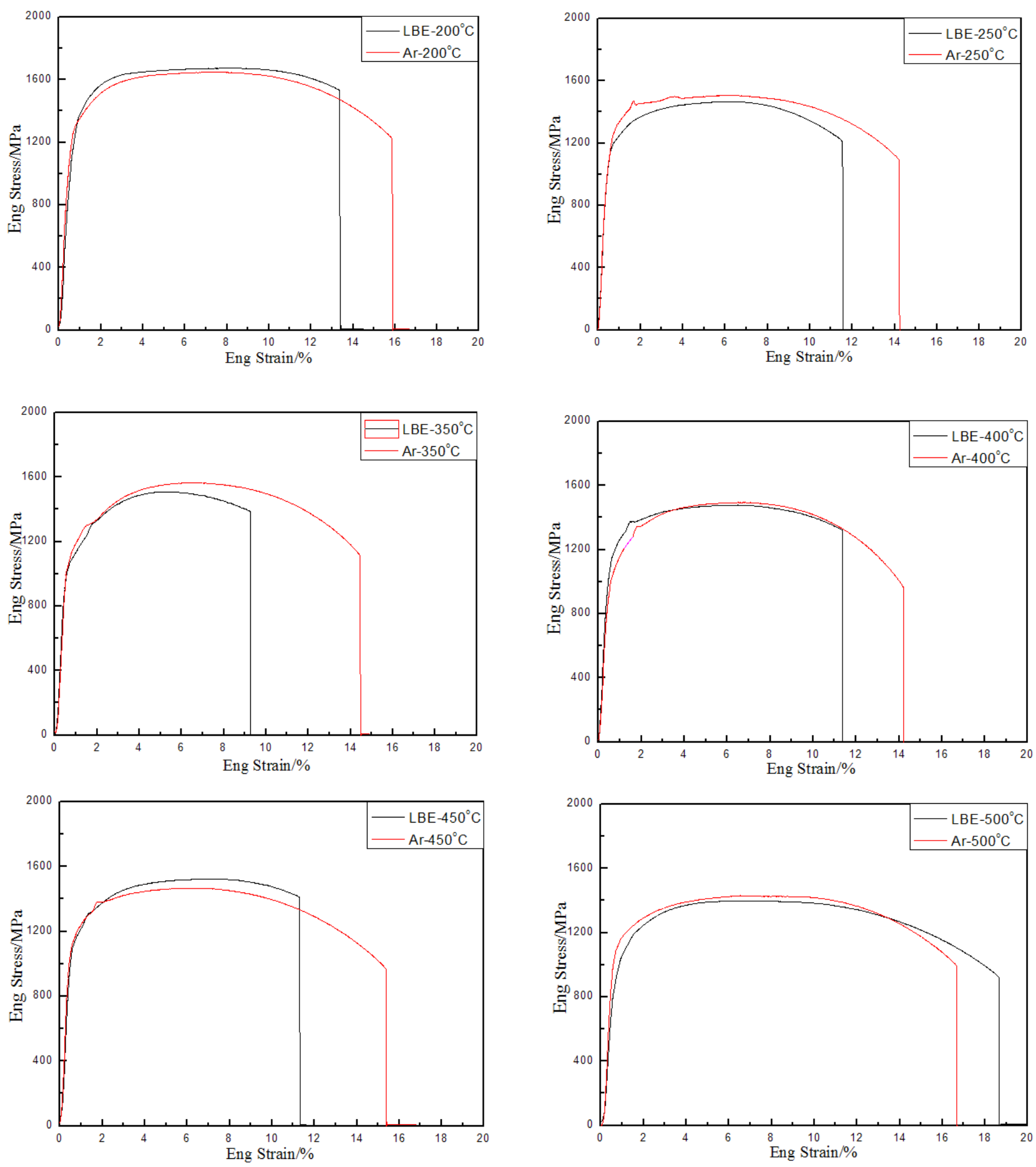

Fig. 8 Tensile curves of SIMP in SSRT. 


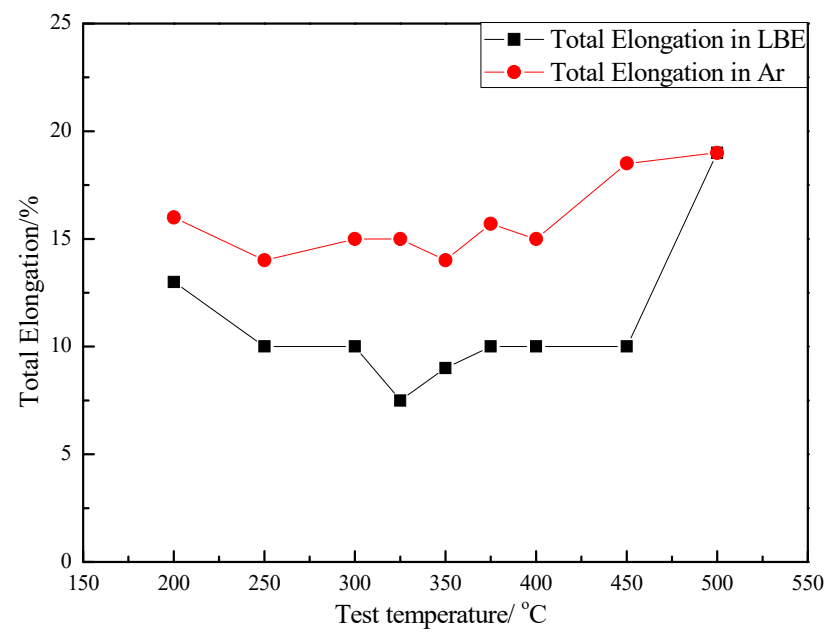

Fig. 9 Total elongation of SIMP as function of temperature (SSRT). 

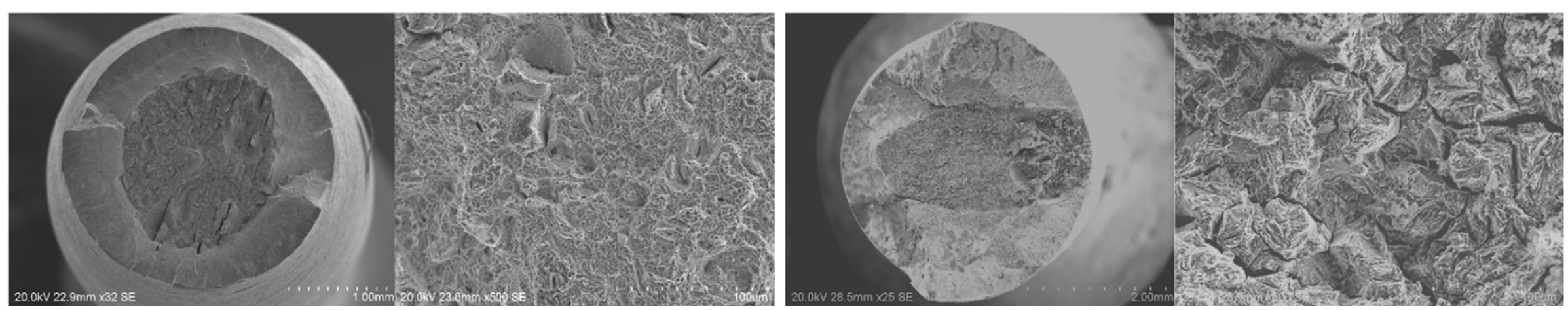

$200{ }^{\circ} \mathrm{C}$
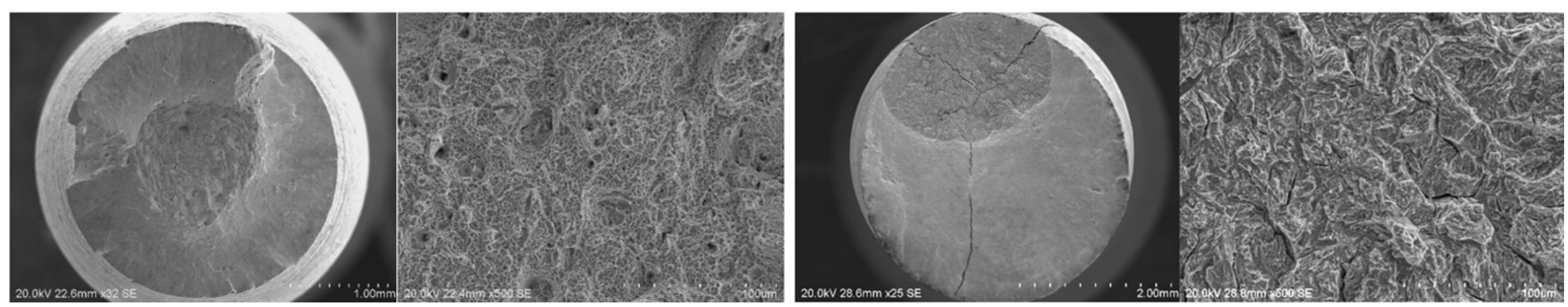

$350{ }^{\circ} \mathrm{C}$
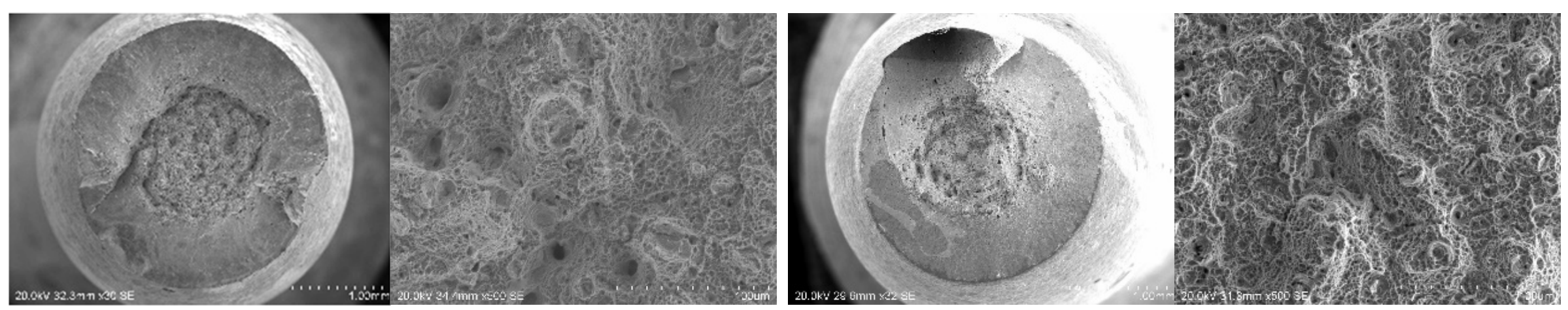

$500{ }^{\circ} \mathrm{C}$

Fig. 10 Fracture analysis of SIMP after SSRT test at different temperatures. 
Highlights

- The tensile behaviors of SIMP steel in LBE are investigated for the first time

- The SIMP is susceptible to LME at different strain rates and temperatures

- The total elongation is reduced greatly

- The ductility trough is wider under SSRT

- The tensile specimens rupture in brittle manner without obvious necking 